\title{
Dietary arsenic intake and subsequent risk of cancer: the Japan Public Health Center-based (JPHC) Prospective Study
}

\author{
Norie Sawada $\cdot$ Motoki Iwasaki • Manami Inoue • \\ Ribeka Takachi $\cdot$ Shizuka Sasazuki • \\ Taiki Yamaji $\cdot$ Taichi Shimazu $\cdot$ Shoichiro Tsugane
}

Received: 16 January 2013/ Accepted: 26 April 2013/Published online: 11 May 2013

(c) The Author(s) 2013. This article is published with open access at Springerlink.com

\begin{abstract}
Purpose Arsenic is a known human carcinogen and has been linked to adverse health outcomes, including cancer. However, the effects of arsenic exposure from food on health are still unknown. We researched to examine the association between arsenic exposure from food and incidence of cancer in a Japanese population.

Methods We conducted a population-based prospective study in 90,378 Japanese men and women aged 45-74 years. Participants responded to a validated questionnaire that included 138 food items. We estimated dietary arsenic intake from 12 food groups (75 items) based on the questionnaire data. During 11 years of follow-up, 7,002 cancer cases were identified. Hazard ratios (HRs) and $95 \%$ confidence intervals (CIs) for cancer were calculated by Cox proportional hazards modeling.

Results Total arsenic and inorganic arsenic showed no association with the risk of total cancer in both men and women. Total arsenic and inorganic arsenic intake tended to be associated with an increased risk of lung cancer in men. In particular, these positive associations were strengthened in currently smoking men, with HRs (95\% CI) in the highest categories of arsenic and inorganic
\end{abstract}

N. Sawada (凹) - M. Iwasaki - M. Inoue · R. Takachi .

S. Sasazuki · T. Yamaji · T. Shimazu · S. Tsugane

Epidemiology and Prevention Division, Research Center for

Cancer Prevention and Screening, National Cancer Center,

5-1-1 Tsukiji, Chuo-ku, Tokyo 104-0045, Japan

e-mail: nsawada@ncc.go.jp

R. Takachi

Division of Social and Environmental Medicine, Department

of Community Preventive Medicine, Niigata University

Graduate School of Medical and Dental Sciences, 1-757

Asahimachi-dori, Chuo-ku, Niigata 951-8510, Japan arsenic intake compared with the lowest of 1.29 (95\% $\mathrm{CI}=1.03-1.61) \quad$ and $1.36 \quad(95 \% \quad \mathrm{CI}=1.09-1.70)$, respectively. We also detected an interaction between arsenic and inorganic arsenic intake and smoking status in men ( $p_{\text {interaction }}<0.01$ and 0.07 , respectively).

Conclusion A significant dose-response trend was seen in the association of arsenic and inorganic intake with lung cancer risk in currently smoking men.

Keywords Arsenic intake - Cancer - Lung cancer . Prospective study

\section{Introduction}

Arsenic is widely distributed in nature, and the general population is exposed to arsenic through air, drinking water, food, and beverages [1]. The International Agency for Research on Cancer documented that arsenic is a group 1 human carcinogen, and there is sufficient evidence to establish that arsenic in drinking water causes cancers of the urinary bladder, lung, and skin in humans [2]. However, most previous studies were conducted among highly exposed populations, namely workers with occupational exposure or drinkers of contaminated well water in Taiwan [3-9], Japan [10-12], Chile [13, 14], Argentina [15-17], and Bangladesh [18].

Although the Japanese Water Supply Law and Ordinance presently restricts arsenic concentration in drinking water to less than $0.01 \mathrm{mg} / \mathrm{L}$, Japanese people commonly consume various seafood and seaweeds which accumulate arsenic [1]. In one study, mean arsenic levels in foods commonly consumed by Japanese were two times higher than those in Western countries, for example, the USA, Canada, and Sweden [19]. Although seafood and seaweeds 
generally contain almost completely nontoxic organic arsenic, for example, arsenosugars [20], arsenosugars detected in seaweeds are metabolized to dimethylarsinic acid in humans, which is more toxic than arsenosugars [21]. Additionally, the edible seaweed hijiki (Hizikia fusiforme), which is often consumed by Japanese people, contains toxic inorganic arsenic [22-24]. However, the effects of arsenic and inorganic arsenic exposure from food on health are still unknown. The possible effects of arsenic and inorganic arsenic on cancer risk are therefore an important public health issue among Japanese, who have relatively high arsenic exposure from food.

Here, we investigated the association between arsenic intake and subsequent cancer in a large prospective cohort study in Japan.

\section{Materials and methods}

\section{Study population}

The Japan Public Health Center-based (JPHC) Prospective Study was launched from 1990 for Cohort I and from 1993 for Cohort II. The study design has been described in detail previously [25]. The participants were recruited in five Public Health Center (PHC) areas (Iwate, Akita, Nagano, Okinawa, and Tokyo) for Cohort I, and in six PHC areas (Ibaraki, Niigata, Kochi, Nagasaki, Okinawa, and Osaka) for Cohort II. In the present analysis, Tokyo subjects were not included in data analyses because incidence data for them were not available. This study was approved by the institutional review board of the National Cancer Center, Tokyo, Japan.

The cohort participants responded to a self-administered questionnaire at baseline in 1990 (Cohort I) and 1993 (Cohort II). A five-year follow-up survey was conducted in 1995 (Cohort I) and 1998 (Cohort II). The five-year followup survey included more comprehensive information on food intake frequency than the baseline survey and accordingly was used as baseline (starting point) for the present study. The questionnaire also included information on medical history and lifestyle factors, such as smoking, alcohol drinking, and others. After exclusion of 11,933 persons who had died, moved out of a study area, or were lost to follow-up before the starting point, the remaining 121,143 subjects were eligible for participation. Of these, 98,513 subjects responded (46,028 men, 52,485 women; response rate $81.3 \%$ ) and were included in the present study.

Assessment of arsenic intake

A self-administered food frequency questionnaire (FFQ) in the 5-year follow-up survey had 138 food and beverage items with standard portions/units and nine frequency categories. A standard portion size was specified for each food item, and respondents were asked to choose their usual portion size from three options (less than half the standard portion size, standard portion size, or more than 1.5 times the standard portion size).

We selected items containing arsenic based on items common to our FFQ and reports from the Ministry of Agriculture, Forestry and Fisheries of Japan [26] and from Ishizaki et al. [27]. Average concentrations reported in these studies were from at least five items in each food. The following 12 food groups (75 items) were then selected: rice (3 items: "boiled rice," "boiled rice cooked with millet or barley," and "rice cake"); wheat (6 items: "bread," "noodle (in Okinawa)," "wheat noodle," "Chinese noodle," "biscuit," and "cake"); soybeans (7 items: "tofu," "yushidofu [predrained tofu]," "koyadofu [freezedried tofu]," "aburaage [deep-fried tofu]," "natto [fermented soybean]," "miso [fermented soybean paste]," and "soy milk"); potatoes (3 items: "potato," "sweet potato," and "taro"); vegetables, including mushrooms (19 items: "Chinese radish," "pickled Chinese radish," "carrot," "cabbage," "broccoli," "Chinese cabbage," "lettuce," "spinach," "onion," "cucumber," "pickled cucumber," "pickled eggplant," "tomato," "tomato juice," "sweet pepper," "shiitake mushroom," "garland chrysanthemum," "pumpkin," and "shimeji mushroom and enoki mushroom"); fruits (12 items: "strawberry," "apple," "orange," "persimmon," "kiwifruit," "melon," "banana," "pear," "grapes," "pineapple," "apple juice," and "orange juice"); seafood (13 items: "bonito," "tuna," "sea bream," "horse mackerel," "saury," "squid," "prawn," "crab shell," "canned tuna," "chikuwa, fish paste product," "kamaboko, fish paste product," "flatfish," and "mackerel"); seaweeds (2 items: "wakame, brown seaweed; and kombu, kelp" and "Nori, dried laver seaweed"); hijiki (1 item: hijiki); meats (5 items: "chicken," "pork," "beef," "chicken liver," and "pork liver"); eggs (1 item: egg); and dairy products (3 items: "milk," "cheese," and "butter"). Arsenic intake was calculated by multiplying the average arsenic concentration in each item by the quantity of each item. We used average arsenic concentrations based on reports from the Ministry of Agriculture, Forestry and Fisheries of Japan [26] and from Ishizaki et al. [27]. The amount of each food consumed (grams/day) was calculated from responses in the FFQ, and total arsenic intake from food was calculated by summing arsenic intake from each item. None of the regions in which our cohorts resided are reported to be arsenic-contaminated areas, other than Niigata Prefecture. However, the Japanese Water Supply Law and Ordinance concerning water limits arsenic in drinking water to less than $0.01 \mathrm{mg} / \mathrm{L}$. Further, wells are not generally used, and the diffusion rate of municipal water supply is more than $99.9 \%$ in the cohort area in 
Niigata (both data from the cohort area in Niigata) [28]. We therefore excluded arsenic in drinking water from consideration. Additionally, we calculated inorganic arsenic intake using reports from the Food Safety Commission of the Cabinet Office [29]. The proportion of inorganic arsenic to total arsenic among food groups is as follows: $86 \%$ in rice, $73 \%$ in hijiki, $10 \%$ in seaweeds other than hijiki, and $5 \%$ in seafood. The proportion of inorganic arsenic to total arsenic among other food groups is assumed to be $100 \%$, because these are unknown [29].

Of the 98,513 subjects who completed the questionnaire, we exclude those with a history of cancer $(n=2,228)$ and those who reported extreme total energy intake (lower and upper 2.5 percentiles: 990 and 4,204 kcal/day in men and 837 and $3,685 \mathrm{kcal} /$ day in women, respectively), leaving 90,378 subjects for final analysis, including 7,002 with cancer. Energy intake was calculated using the Fifth Revised Edition of the Standard Tables of Food Composition in Japan [30].

To evaluate the validity of energy-adjusted arsenic intake, we compared estimates from the FFQ with 28-day (or 14-day for the Okinawa PHC area) dietary records from a subsample of the cohort. Spearman's rank correlation coefficients for arsenic and inorganic arsenic were 0.30 and 0.33 in men and 0.15 and 0.19 in women, respectively.

\section{Follow-up and identification of cancer cases}

We followed up all registered cohort subjects from the starting point until 31 December 2008. Residency registration and death registration are required by the Basic Residential Register Law and Family Registry Law, respectively, and the registries are thought to be complete. During the follow-up period in the present study, 9,370 subjects died, 2,951 moved out of the study area, and 298 $(0.3 \%)$ were lost to follow-up.

The occurrence of cancer was identified by active patient notification from major local hospitals in the study area and from data linkage with population-based cancer registries, with permission from each of the local governments responsible for the cancer registries. Information on the cause of death was supplemented by death certificate information, with permission. Cases were coded using the International Classification of Diseases for Oncology, Third Edition (ICD-O-3). The proportion of cases ascertained by death certificate only (DCO) was $6.1 \%$. These ratios were considered satisfactory for the present study. For the present analysis, the earliest date of diagnosis was used in cases with multiple primary cancers diagnosed at different times.

\section{Statistical analysis}

Person-years of follow-up were calculated for each subject from the date of the starting point to the date of cancer diagnosis, date of relocation from the study area, date of death, or end of the study period (31 December 2008), whichever occurred first. For subjects who were lost to follow-up, the last confirmed date of presence in the study area was used as the date of censor.

The Cox proportional hazards model was used to estimate hazard ratios (HRs) and $95 \%$ confidence intervals (CIs) of cancer by energy-adjusted arsenic intake using the SAS program (PROC PHREG) (SAS Institute Inc., Cary, NC, USA). Arsenic is included in a lot of foods, and thus increasing intake of various foods is speculated as increasing arsenic and energy intake. Thus, energy adjustment of arsenic intake was done using the residual method [31].

HRs were adjusted for the following potential confounding factors: age at the starting point (five-year groups), PHC area, smoking status (never, former, and current: $<20,21-40$, or $\geq 41$ cigarettes/d), alcohol intake (almost never, less than 3-4 times/week, and more than 5-6 times/week), body mass index $(<21,21-23,23-25$, and $\geq 25$ ), and sports in leisure time (almost none, less than 1-2 times/week, and more than 3-4 times/week) in the analysis of the association between arsenic and cancer. Moreover, women were further adjusted for menopausal status (premenopausal and postmenopausal) and use of exogenous female hormones (yes or no). These variables, obtained from the questionnaire, are either known or suspected risk factors for cancer that have been identified in the previous studies. Furthermore, we adjusted for screening examination (chest radiograph, gastric radiograph, gastrointestinal endoscopy, fecal occult blood test, barium enema, colonoscopy for men and women, mammography, and Papanicolaou smear for women) and nuclear family (father, mother, brothers, and sisters) history of any cancer, but the results did not substantially change. Therefore, we did not adjust for screening examination or family history of cancer in the final model.

Because of potential synergistic effects between arsenic and smoking on lung cancer $[6,11,18,32]$, we then tested effect modification by smoking status (never and ever) through the addition of cross-product terms into the multivariate model. Trends were assessed by assignment of the ordinal value. All $p$ values were two-sided, and statistical significance was determined at the $p<0.05$ level.

\section{Results}

The average estimated energy-adjusted arsenic intake in the cohort was $170.0 \mu \mathrm{g} / \mathrm{d}$. Seafood, hijiki, seaweeds, rice, and vegetables contributed $32,28,20,16$, and $1 \%$ of total arsenic intake, respectively. Other food groups contributed less than $1 \%$ of arsenic intake. Hijiki, rice, seaweeds, 


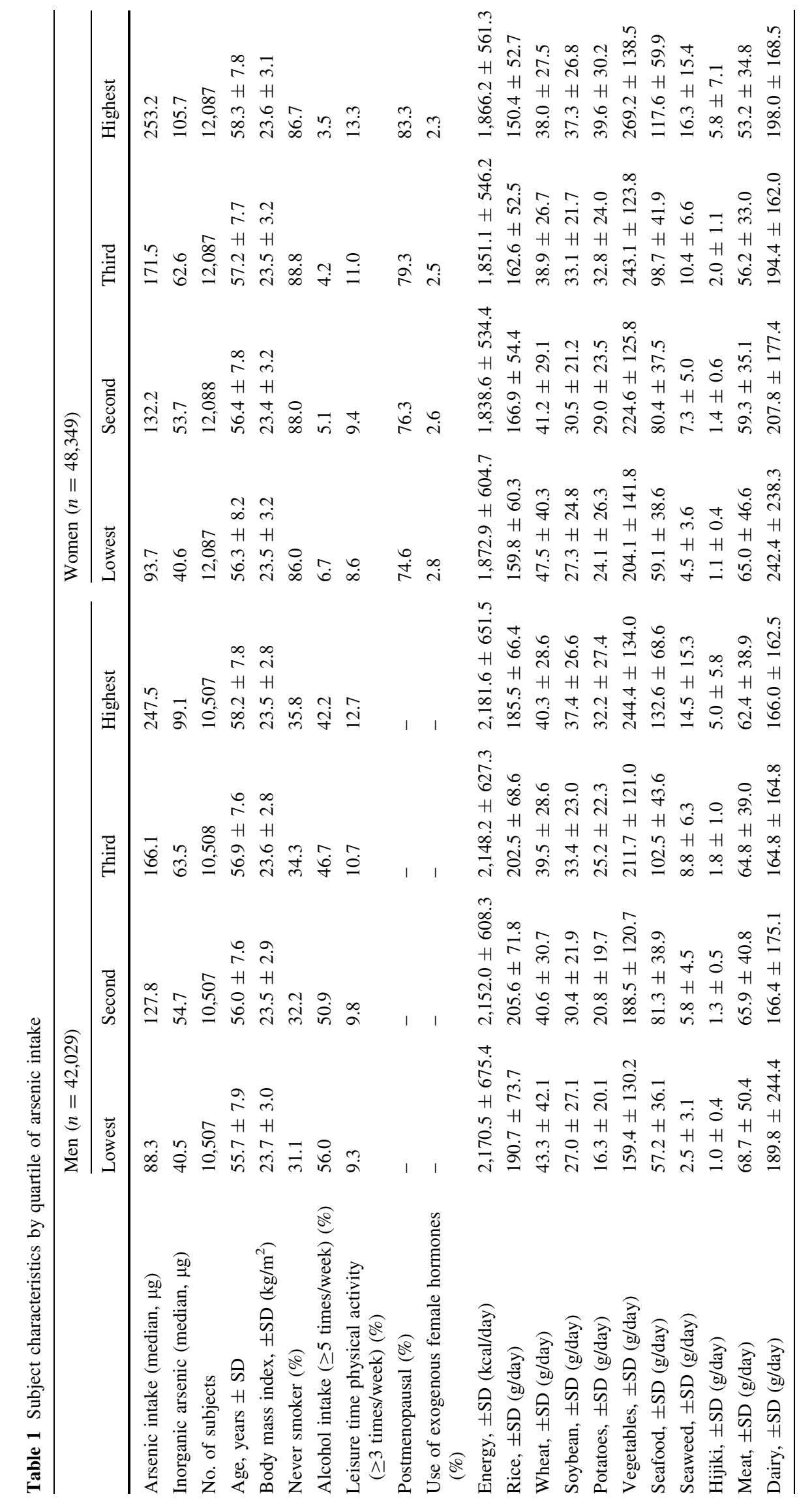


Table 2 Hazard ratios for total cancer incidence by quartile of arsenic and inorganic arsenic intake

\begin{tabular}{|c|c|c|c|c|c|}
\hline & \multicolumn{4}{|c|}{ Intake by quartile } & \multirow[t]{2}{*}{$p_{\text {trenc }}$} \\
\hline & Lowest & Second & Third & Highest & \\
\hline \multicolumn{6}{|l|}{ Arsenic } \\
\hline \multicolumn{6}{|l|}{ Men } \\
\hline Median intake $(\mu \mathrm{g} /$ day $)$ & 88.8 & 127.8 & 166.1 & 247.5 & \\
\hline Number of cases & 1,002 & 1,038 & 1,116 & 1,167 & \\
\hline Person-years of follow-up & 112,502 & 112,696 & 112,003 & 109,158 & \\
\hline Age-area-adjusted HR (95\% CI) & 1.00 & $1.00(0.92-1.09)$ & $0.99(0.91-1.08)$ & $0.98(0.89-1.06)$ & 0.56 \\
\hline Multivariate HR (95\% CI) & 1.00 & $1.01(0.92-1.11)$ & $1.04(0.94-1.14)$ & $1.03(0.94-1.13)$ & 0.50 \\
\hline \multicolumn{6}{|l|}{ Women } \\
\hline Median intake $(\mu \mathrm{g} /$ day $)$ & 93.7 & 132.2 & 171.5 & 25.3 & \\
\hline Number of cases & 635 & 646 & 715 & 683 & \\
\hline Person-years of follow-up & 133,894 & 135,104 & 134,924 & 132,963 & \\
\hline Age-area-adjusted HR (95 \% CI) & 1.00 & $0.99(0.89-1.10)$ & $1.05(0.95-1.18)$ & $0.98(0.88-1.10)$ & 0.96 \\
\hline Multivariate HR (95\% CI) & 1.00 & $0.99(0.88-1.12)$ & $1.07(0.96-1.21)$ & $0.98(0.87-1.10)$ & 0.94 \\
\hline \multicolumn{6}{|l|}{ Inorganic arsenic } \\
\hline \multicolumn{6}{|l|}{ Men } \\
\hline Median intake $(\mu \mathrm{g} /$ day $)$ & 36.5 & 51.4 & 64.7 & 102.2 & \\
\hline Number of cases & 1,084 & 1,072 & 1,042 & 1,125 & \\
\hline Person-years of follow-up & 111,399 & 112,541 & 112,403 & 110,017 & \\
\hline Age-area-adjusted HR (95 \% CI) & 1.00 & $0.96(0.88-1.05)$ & $0.91(0.83-0.99)$ & $0.94(0.86-1.02)$ & 0.09 \\
\hline Multivariate HR (95 \% CI) & 1.00 & $0.98(0.89-1.07)$ & $0.95(0.87-1.05)$ & $1.00(0.91-1.10)$ & 0.92 \\
\hline \multicolumn{6}{|l|}{ Women } \\
\hline Median intake ( $\mu \mathrm{g} /$ day) & 37.1 & 51.2 & 64.1 & 107.6 & \\
\hline Number of cases & 634 & 649 & 722 & 674 & \\
\hline Person-years of follow-up & 134,833 & 134,486 & 134,491 & 133,075 & \\
\hline Age-area-adjusted HR (95 \% CI) & 1.00 & $1.02(0.91-1.14)$ & $1.10(0.99-1.23)$ & $1.02(0.91-1.14)$ & 0.51 \\
\hline Multivariate HR (95\% CI) & 1.00 & $1.00(0.89-1.12)$ & $1.08(0.96-1.22)$ & $0.99(0.87-1.11)$ & 0.85 \\
\hline
\end{tabular}

Multivariate HRs were adjusted for age, area, body mass index, smoking status, frequency of alcohol intake, and leisure time physical activity.

They were further adjusted for menopausal status and use of exogenous female hormones in women

seafood, vegetables, and fruits contributed $50,35,5,4,3$, and $2 \%$ of inorganic arsenic intake, respectively. Other food groups contributed less than $1 \%$ of inorganic arsenic intake.

During 983,245 person-years of follow-up (average follow-up period 10.9 years) for 90,378 subjects $(42,029$ men and 48,349 women), there were 7,002 newly diagnosed cases of cancer (4,323 in men and 2,679 in women). In men, gastric cancer was the most common $(n=781$, $18 \%$ ), followed by cancers of the lung ( $n=685,16 \%$ ), colorectum $(n=681,16 \%)$, and prostate $(n=595$, $14 \%)$. In women, the most common cancers were colorectal cancer $(n=481,18 \%)$, followed by cancers of the breast $(n=470,18 \%)$, stomach $(n=328,12 \%)$, and lung $(n=290,11 \%)$.

The characteristics of participants according to arsenic intake are shown in Table 1. Men and women with higher arsenic intake tended to be older, smoke less, drink less alcohol, and consume less rice, wheat, meat, and dairy products and consume more soybeans, potatoes, vegetables, seaweeds, seafood, and hijiki. In women with higher arsenic intake, the proportion of postmenopausal women was high and use of exogenous female hormones was low.

Table 2 shows the association of arsenic and inorganic arsenic intake with total cancer incidence. No relationship was observed between arsenic and total cancer, with HRs for the highest versus lowest quartile of 1.03 (95\% $\mathrm{CI}=0.94-1.13)$ for men and $0.98(0.87-1.10)$ for women. Furthermore, no association was also shown between inorganic arsenic and total cancer, with HRs for the highest versus lowest quartile of $1.00(95 \% \mathrm{CI}=0.91$ to 1.10$)$ for men and 0.99 (0.87 to 1.11) for women.

On additional analysis that used specific cancers as endpoints, higher consumption of arsenic was associated with a higher risk of lung cancer in men (Table 3), although the linear trend was not significant (multivariable $\mathrm{HR}$ in the third and highest categories $(\mathrm{HR}=1.35,95 \%$ $\mathrm{CI}=1.06-1.72 ;$ and $\mathrm{HR}=1.23,95 \% \mathrm{CI}=0.96-1.57$, respectively)). In contrast, no association was shown 
Table 3 Hazard ratios for incidence of cancer at specific sites by quartile of arsenic intake in men

\begin{tabular}{|c|c|c|c|c|c|}
\hline & \multicolumn{4}{|c|}{ Intake by quartile } & \multirow[t]{2}{*}{$p_{\text {trend }}$} \\
\hline & Lowest & Second & Third & Highest & \\
\hline \multicolumn{6}{|l|}{ Men } \\
\hline \multicolumn{6}{|l|}{ Stomach } \\
\hline Number of cases & 141 & 188 & 171 & 186 & \\
\hline Multivariate HR (95\% CI) & 1.00 & $1.18(0.94-1.47)$ & $1.00(0.80-1.25)$ & $1.09(0.87-1.37)$ & 0.86 \\
\hline \multicolumn{6}{|l|}{ Colorectal } \\
\hline Number of cases & 150 & 142 & 150 & 159 & \\
\hline Multivariate $\mathrm{HR}(95 \% \mathrm{CI})$ & 1.00 & $0.94(0.75-1.19)$ & $0.96(0.76-1.21)$ & $1.01(0.80-1.28)$ & 0.88 \\
\hline \multicolumn{6}{|l|}{ Liver } \\
\hline Number of cases & 61 & 57 & 82 & 85 & \\
\hline Multivariate $\mathrm{HR}(95 \% \mathrm{CI})$ & 1.00 & $0.79(0.55-1.13)$ & $1.01(0.72-1.42)$ & $0.93(0.66-1.32)$ & 0.89 \\
\hline \multicolumn{6}{|l|}{ Pancreas } \\
\hline Number of cases & 29 & 44 & 39 & 30 & \\
\hline Multivariate HR $(95 \% \mathrm{CI})$ & 1.00 & $1.33(0.83-2.13)$ & $1.10(0.67-1.80)$ & $0.84(0.50-1.43)$ & 0.35 \\
\hline \multicolumn{6}{|l|}{ Lung } \\
\hline Number of cases & 119 & 144 & 174 & 162 & \\
\hline Multivariate HR (95 \% CI) & 1.00 & $1.18(0.92-1.51)$ & $1.35(1.06-1.72)$ & $1.23(0.96-1.57)$ & 0.07 \\
\hline \multicolumn{6}{|l|}{ Prostate } \\
\hline Number of cases & 111 & 119 & 142 & 148 & \\
\hline Multivariate HR (95\% CI) & 1.00 & $0.99(0.76-1.28)$ & $1.06(0.82-1.37)$ & $1.08(0.83-1.39)$ & 0.47 \\
\hline \multicolumn{6}{|l|}{ Bladder } \\
\hline Number of cases & 33 & 36 & 35 & 37 & \\
\hline Multivariate HR (95\% CI) & 1.00 & $1.01(0.62-1.62)$ & $0.90(0.55-1.47)$ & $0.95(0.58-1.55)$ & 0.74 \\
\hline \multicolumn{6}{|l|}{ Kidney } \\
\hline Number of cases & 17 & 20 & 23 & 23 & \\
\hline Multivariate HR (95\% CI) & 1.00 & $1.22(0.64-2.35)$ & $1.41(0.74-2.67)$ & $1.44(0.75-2.75)$ & 0.25 \\
\hline
\end{tabular}

Multivariate HRs were adjusted for age, area, body mass index, smoking status, frequency of alcohol intake, and leisure time physical activity

between arsenic intake and any specific cancer in women (Table 4), including lung cancer.

Additionally, we observed a positive association between inorganic arsenic intake and lung and kidney cancer risk in men (Table 5). The multivariate HRs of lung cancer across increasing quartiles of inorganic arsenic were $1.00,1.15,1.19$, and $1.28\left(95 \% \mathrm{CI}=1.00-1.62 ; p_{\text {trend }}=\right.$ 0.05). For kidney cancer, the multivariate HRs across increasing quartiles of inorganic arsenic were 1.00, 1.72, 1.66 , and 2.05 (95\% CI $\left.=1.05-4.03 ; p_{\text {trend }}=0.06\right)$. Similar findings in lung cancer were observed in women, albeit without statistical significance (Table 6). Multivariable HR for the highest versus lowest quartile of inorganic arsenic was 1.37 (95\% CI $\left.=0.95-1.98, p_{\text {trend }}=0.08\right)$.

No substantial changes in results were seen after stratifying by age and body mass index; on analysis by decile of arsenic and inorganic intake; or after further adjustment for additional nutrition factors, such as fiber and calcium intake (data not shown). Furthermore, our analyses did not change when restricted to cases that occurred after the first 3 years of follow-up (data not shown).
To evaluate potential synergistic effects between arsenic and smoking on lung cancer, we also assessed the effect of arsenic and inorganic arsenic intake on lung cancer according to smoking status (Table 7). Arsenic intake was inversely associated with lung cancer risk in never smokers (highest tertile compared with lowest, multivariate HR $=0.49(95 \%$ $\mathrm{CI}=0.27-0.86), \quad p$ for trend $=0.01)$. In contrast, we observed that HRs increased as arsenic intake increased among current smokers (highest tertile compared with lowest, multivariate $\mathrm{HR}=1.37 \quad(95 \% \mathrm{CI}=1.06-1.77), \quad p$ for trend $=0.03$ ) and detected an interaction between arsenic intake and smoking status $\left(p_{\text {interaction }}<0.01\right)$. Similarly, we detected an increased risk among current smokers who had a high intake of inorganic arsenic (highest tertile compared with lowest, multivariate $\mathrm{HR}=1.38$ (95\% CI = 1.07-1.77), $p$ for trend $=0.01$ ) and an interaction between inorganic arsenic intake and smoking status $\left(p_{\text {interaction }}=0.07\right)$. In never-smoking women, inorganic arsenic was positively associated with lung cancer risk (HR for the highest versus lowest tertile was 1.57 (95\% CI $=1.12-2.20)$ ) and arsenic intake slightly increased the risk of lung cancer (HR for the 
Table 4 Hazard ratios for incidence of cancer at specific sites by quartile of arsenic intake in women

\begin{tabular}{|c|c|c|c|c|c|}
\hline & \multicolumn{4}{|c|}{ Intake by quartile } & \multirow[t]{2}{*}{$p_{\text {trend }}$} \\
\hline & Lowest & Second & Third & Highest & \\
\hline \multicolumn{6}{|l|}{ Women } \\
\hline \multicolumn{6}{|l|}{ Stomach } \\
\hline Number of cases & 63 & 71 & 64 & 75 & \\
\hline Multivariate HR (95\% CI) & 1.00 & $0.99(0.70-1.39)$ & $0.84(0.59-1.19)$ & $0.96(0.68-1.36)$ & 0.64 \\
\hline \multicolumn{6}{|l|}{ Colorectal } \\
\hline Number of cases & 97 & 97 & 117 & 107 & \\
\hline Multivariate HR (95 \% CI) & 1.00 & $0.98(0.74-1.30)$ & $1.15(0.97-1.51)$ & $1.05(0.79-1.39)$ & 0.51 \\
\hline \multicolumn{6}{|l|}{ Liver } \\
\hline Number of cases & 21 & 33 & 34 & 29 & \\
\hline Multivariate HR (95 \% CI) & 1.00 & $1.36(0.78-2.37)$ & $1.28(0.74-2.23)$ & $1.05(0.59-1.87)$ & 0.95 \\
\hline \multicolumn{6}{|l|}{ Pancreas } \\
\hline Number of cases & 26 & 21 & 34 & 24 & \\
\hline Multivariate HR (95 \% CI) & 1.00 & $0.80(0.44-1.39)$ & $1.17(0.69-1.99)$ & $0.81(0.45-1.43)$ & 0.81 \\
\hline \multicolumn{6}{|l|}{ Lung } \\
\hline Number of cases & 60 & 54 & 66 & 74 & \\
\hline Multivariate HR (95\% CI) & 1.00 & $0.89(0.61-1.29)$ & $1.05(0.74-1.51)$ & $1.16(0.81-1.65)$ & 0.28 \\
\hline \multicolumn{6}{|l|}{ Breast } \\
\hline Number of cases & 102 & 100 & 124 & 105 & \\
\hline Multivariate HR (95\% CI) & 1.00 & $0.95(0.72-1.26)$ & $1.19(0.91-1.56)$ & $1.06(0.80-1.41)$ & 0.35 \\
\hline \multicolumn{6}{|l|}{ Endometrial } \\
\hline Number of cases & 18 & 21 & 19 & 20 & \\
\hline Multivariate HR (95\% CI) & 1.00 & $1.13(0.60-2.14)$ & $1.08(0.56-2.08)$ & $1.23(0.64-2.37)$ & 0.58 \\
\hline \multicolumn{6}{|l|}{ Bladder } \\
\hline Number of cases & 7 & 9 & 10 & 7 & \\
\hline Multivariate HR (95\% CI) & 1.00 & $1.37(0.50-3.73)$ & $1.61(0.60-4.34)$ & $1.17(0.40-3.44)$ & 0.70 \\
\hline \multicolumn{6}{|l|}{ Kidney } \\
\hline Number of cases & 8 & 9 & 13 & 4 & \\
\hline Multivariate HR (95 \% CI) & 1.00 & $1.03(0.39-2.71)$ & $1.53(0.62-3.78)$ & $0.48(0.14-1.64)$ & 0.50 \\
\hline
\end{tabular}

Multivariate HRs were adjusted for age, area, body mass index, smoking status, frequency of alcohol intake, leisure time physical activity, menopausal status, and use of exogenous female hormones

highest versus lowest tertile was $1.25(95 \% \mathrm{CI}=0.90$ $1.75)$ ), although no interaction was detected in women $\left(p_{\text {interaction }}\right.$ for arsenic and inorganic arsenic 0.14 and 0.31, respectively).

With regard to hijiki, which had the highest ratio of inorganic arsenic, although hijiki intake showed a slight positive association with lung cancer in ever-smoking men (highest tertile compared with lowest, multivariate $\mathrm{HR}=1.22(95 \% \mathrm{CI}=0.995-1.51), p$ for trend $=0.05)$, we did not detect an interaction between hijiki intake and smoking status $\left(p_{\text {interaction }}=0.54\right)$. In women, although hijiki intake was positively associated with lung cancer risk in never-smoking women (HR for the highest versus lowest tertile 1.46 (95\% CI = 1.06-2.01)), we did not detect an interaction between hijiki intake and smoking status $\left(p_{\text {interaction }}=0.12\right)($ data not shown $)$.

\section{Discussion}

Here, we investigated the association between arsenic intake and the risk of cancer in a population-based prospective study in Japan. Although we saw no overall association between arsenic and inorganic arsenic intake and total cancer, results showed an increased risk of lung cancer in men with a higher consumption of arsenic and inorganic arsenic, especially among currently smoking men. Of particular note, we showed that cigarette smoking had a modifying effect on the association between arsenic intake and lung cancer.

Many studies have reported that arsenic intake through drinking water is positively associated with the risk of cancers of the lung [5-7, 9-14, 16, 18, 32, 33], bladder [5, $7-9,13-15,17,33,34]$, kidney [13, 16, 33], and liver [5, 9, 
Table 5 Hazard ratios for incidence of cancer at specific sites by quartile of inorganic arsenic intake in men

\begin{tabular}{|c|c|c|c|c|c|}
\hline & \multicolumn{4}{|c|}{ Intake by quartile } & \multirow[t]{2}{*}{$p_{\text {trend }}$} \\
\hline & Lowest & Second & Third & Highest & \\
\hline \multicolumn{6}{|l|}{ Men } \\
\hline \multicolumn{6}{|l|}{ Stomach } \\
\hline Number of cases & 164 & 188 & 166 & 168 & \\
\hline Multivariate HR (95\% CI) & 1.00 & $1.02(0.83-1.26)$ & $0.88(0.70-1.10)$ & $0.89(0.71-1.11)$ & 0.16 \\
\hline \multicolumn{6}{|l|}{ Colorectal } \\
\hline Number of cases & 152 & 161 & 133 & 155 & \\
\hline Multivariate HR (95 \% CI) & 1.00 & $1.09(0.87-1.37)$ & $0.91(0.72-1.16)$ & $1.05(0.83-1.32)$ & 0.93 \\
\hline \multicolumn{6}{|l|}{ Liver } \\
\hline Number of cases & 68 & 49 & 78 & 90 & \\
\hline Multivariate HR (95 \% CI) & 1.00 & $0.62(0.43-0.90)$ & $0.87(0.62-1.22)$ & $0.94(0.67-1.31)$ & 0.67 \\
\hline \multicolumn{6}{|l|}{ Pancreas } \\
\hline Number of cases & 34 & 31 & 46 & 31 & \\
\hline Multivariate HR (95 \% CI) & 1.00 & $0.80(0.49-1.32)$ & $1.14(0.72-1.80)$ & $0.78(0.47-1.29)$ & 0.66 \\
\hline \multicolumn{6}{|l|}{ Lung } \\
\hline Number of cases & 131 & 147 & 153 & 168 & \\
\hline Multivariate HR (95 \% CI) & 1.00 & $1.15(0.91-1.47)$ & $1.19(0.93-1.52)$ & $1.28(1.00-1.62)$ & 0.05 \\
\hline \multicolumn{6}{|l|}{ Prostate } \\
\hline Number of cases & 134 & 128 & 122 & 136 & \\
\hline Multivariate HR (95 \% CI) & 1.00 & $0.83(0.73-1.19)$ & $0.85(0.65-1.10)$ & $0.92(0.71-1.18)$ & 0.42 \\
\hline \multicolumn{6}{|l|}{ Bladder } \\
\hline Number of cases & 28 & 41 & 26 & 46 & \\
\hline Multivariate HR (95 \% CI) & 1.00 & $1.45(0.89-2.37)$ & $0.89(0.51-1.55)$ & $1.56(0.95-2.55)$ & 0.24 \\
\hline \multicolumn{6}{|l|}{ Kidney } \\
\hline Number of cases & 14 & 22 & 21 & 26 & \\
\hline Multivariate HR (95 \% CI) & 1.00 & $1.72(0.87-3.39)$ & $1.66(0.83-3.35)$ & $2.05(1.05-4.03)$ & 0.06 \\
\hline
\end{tabular}

Multivariate HRs were adjusted for age, area, body mass index, smoking status, frequency of alcohol intake, and leisure time physical activity

16, 33]. Currently, the mechanisms of arsenic toxicity are considered to involve the role of oxidative stress, enhanced cell proliferation, and modulation of gene expression. In humans, inorganic arsenic ingested through drinking water is taken up through the blood and distributed primarily to the liver, kidneys, lungs, and other organs [35, 36]. Additionally, recent studies have shown that arsenic exposure decreases DNA repair capacity [37, 38].

In 2004 and 2010, the Food Standards Agency (FSA) of the United Kingdom advised against the consumption of hijiki [39] owing to its high levels of inorganic arsenic, which is a suspected carcinogen. In response, the Japanese Ministry of Health, Labor, and Welfare (MHLW) announced that hijiki consumption does not confer an adverse effect on health, on the basis of its estimation that inorganic arsenic intake through hijiki does not exceed the Provisional Tolerable Weekly Intake (PTWI) of $15 \mu \mathrm{g} / \mathrm{kg} /$ week, as defined by the WHO [40]. In 2010, however, the Joint FAO/WHO Expert Committee on Food Additives (JECFA) reported that the lower limit on the benchmark dose of inorganic arsenic causing a $0.5 \%$ increase in the incidence of lung cancer (BMDL0.5) was determined from epidemiological studies to be $3.0 \mu \mathrm{g} / \mathrm{kg}$ bw per day (2-7 $\mu \mathrm{g} / \mathrm{kg}$ bw per day based on the range of estimated total dietary exposure), using a range of assumptions to estimate total dietary exposure to inorganic arsenic from drinking water and food. The Committee noted that the PTWI ( $15 \mu \mathrm{g} / \mathrm{kg}$ bw is equivalent to $2.1 \mu \mathrm{g} / \mathrm{kg}$ bw per day) is in the region of the BMDL0.5 and was therefore no longer appropriate [41]. Thus, studies on the association between arsenic intake and cancer have been sought. Despite the fact that Japanese people consume seaweeds, including hijiki, on a daily basis, no research on the association between arsenic intake through food and cancer has appeared, albeit that a few papers have investigated the association between drinking water and mortality in a contaminated area. In those studies, drinking water contaminated with arsenic from a factory in the town of Nakajo in Niigata Prefecture, Japan, was associated with a significantly elevated ratio of observed to expected deaths 
Table 6 Hazard ratios for incidence of cancer at specific sites by quartile of inorganic arsenic intake in women

\begin{tabular}{|c|c|c|c|c|c|}
\hline & \multicolumn{4}{|c|}{ Intake by quartile } & \multirow[t]{2}{*}{$p_{\text {trend }}$} \\
\hline & Lowest & Second & Third & Highest & \\
\hline \multicolumn{6}{|l|}{ Women } \\
\hline \multicolumn{6}{|l|}{ Stomach } \\
\hline Number of cases & 65 & 61 & 74 & 73 & \\
\hline Multivariate HR (95\% CI) & 1.00 & $0.82(0.57-1.16)$ & $0.93(0.66-1.30)$ & $0.92(0.65-1.29)$ & 0.86 \\
\hline \multicolumn{6}{|l|}{ Colorectal } \\
\hline Number of cases & 109 & 89 & 113 & 107 & \\
\hline Multivariate HR (95 \% CI) & 1.00 & $0.83(0.62-1.10)$ & $1.02(0.78-1.34)$ & $0.97(0.73-1.28)$ & 0.80 \\
\hline \multicolumn{6}{|l|}{ Liver } \\
\hline Number of cases & 21 & 32 & 36 & 28 & \\
\hline Multivariate HR (95 \% CI) & 1.00 & $1.36(0.78-2.38)$ & $1.41(0.81-2.46)$ & $1.10(0.61-1.97)$ & 0.83 \\
\hline \multicolumn{6}{|l|}{ Pancreas } \\
\hline Number of cases & 20 & 31 & 27 & 27 & \\
\hline Multivariate HR (95 \% CI) & 1.00 & $1.62(0.91-2.88)$ & $1.38(0.76-2.51)$ & $1.37(0.75-2.49)$ & 0.49 \\
\hline \multicolumn{6}{|l|}{ Lung } \\
\hline Number of cases & 53 & 61 & 68 & 72 & \\
\hline Multivariate HR (95 \% CI) & 1.00 & $1.18(0.81-1.71)$ & $1.29(0.89-1.87)$ & $1.37(0.95-1.98)$ & 0.08 \\
\hline \multicolumn{6}{|l|}{ Breast } \\
\hline Number of cases & 101 & 114 & 116 & 100 & \\
\hline Multivariate HR (95 \% CI) & 1.00 & $1.12(0.86-1.48)$ & $1.16(0.88-1.52)$ & $1.02(0.77-1.36)$ & 0.84 \\
\hline \multicolumn{6}{|l|}{ Endometrial } \\
\hline Number of cases & 23 & 17 & 19 & 19 & \\
\hline Multivariate HR (95 \% CI) & 1.00 & $0.73(0.39-1.37)$ & $0.81(0.44-1.51)$ & $0.86(0.46-1.60)$ & 0.71 \\
\hline \multicolumn{6}{|l|}{ Bladder } \\
\hline Number of cases & 6 & 10 & 10 & 7 & \\
\hline Multivariate HR (95\% CI) & 1.00 & $1.96(0.70-5.53)$ & $2.06(0.72-5.87)$ & $1.54(0.50-4.73)$ & 0.47 \\
\hline \multicolumn{6}{|l|}{ Kidney } \\
\hline Number of cases & 13 & 7 & 5 & 9 & \\
\hline Multivariate HR (95 \% CI) & 1.00 & $0.48(0.19-1.23)$ & $0.34(0.12-0.96)$ & $0.64(0.27-1.53)$ & 0.24 \\
\hline
\end{tabular}

Multivariate HRs were adjusted for age, area, body mass index, smoking status, frequency of alcohol intake, leisure time physical activity, menopausal status, and use of exogenous female hormones

from lung cancer [10-12]. Our present study also showed that a higher intake of arsenic increased the risk of lung cancer and is the first prospective study to observe a positive association between lung cancer and arsenic intake through food in a general population.

Additionally, several studies have suggested an apparent synergistic effect between a high level of arsenic exposure and cigarette smoking in men [6, 11, 18, 32, 34, 42-44]. A meta-analysis of studies on occupational arsenic exposure from inhalation found a synergistic effect of cigarette smoking and arsenic on lung cancer, with 30 to $54 \%$ of lung cancer cases attributable to both exposures [45]. Consistent with these previous papers, our study also provided evidence of synergism between arsenic intake and smoking in the development of lung cancer. A previous study showed that metabolism of arsenic related to glutathione S-transferase M1 and T1 [46]. Hays et al. [47] showed that combined exposure to arsenic and cigarette smoke leads to the depletion of total glutathione stores in the lung. Additionally, they also suggested that arsenic and cigarette smoke increased DNA oxidation. These findings indicate that smokers might be more susceptible than nonsmokers to arsenic exposure.

Seaweed is consumed on a daily basis in a traditional Japanese diet. Seaweeds are rich in minerals and dietary fiber [48-50], and dietary seaweeds have been reported to have antioxidant and antimutagenic effects in experimental studies [51, 52]. A case-control study showed an inverse association between seaweed intake and breast cancer risk [53]. Although our study showed no association between arsenic intake and breast cancer, intake was inversely associated with lung cancer among never-smoking men. 


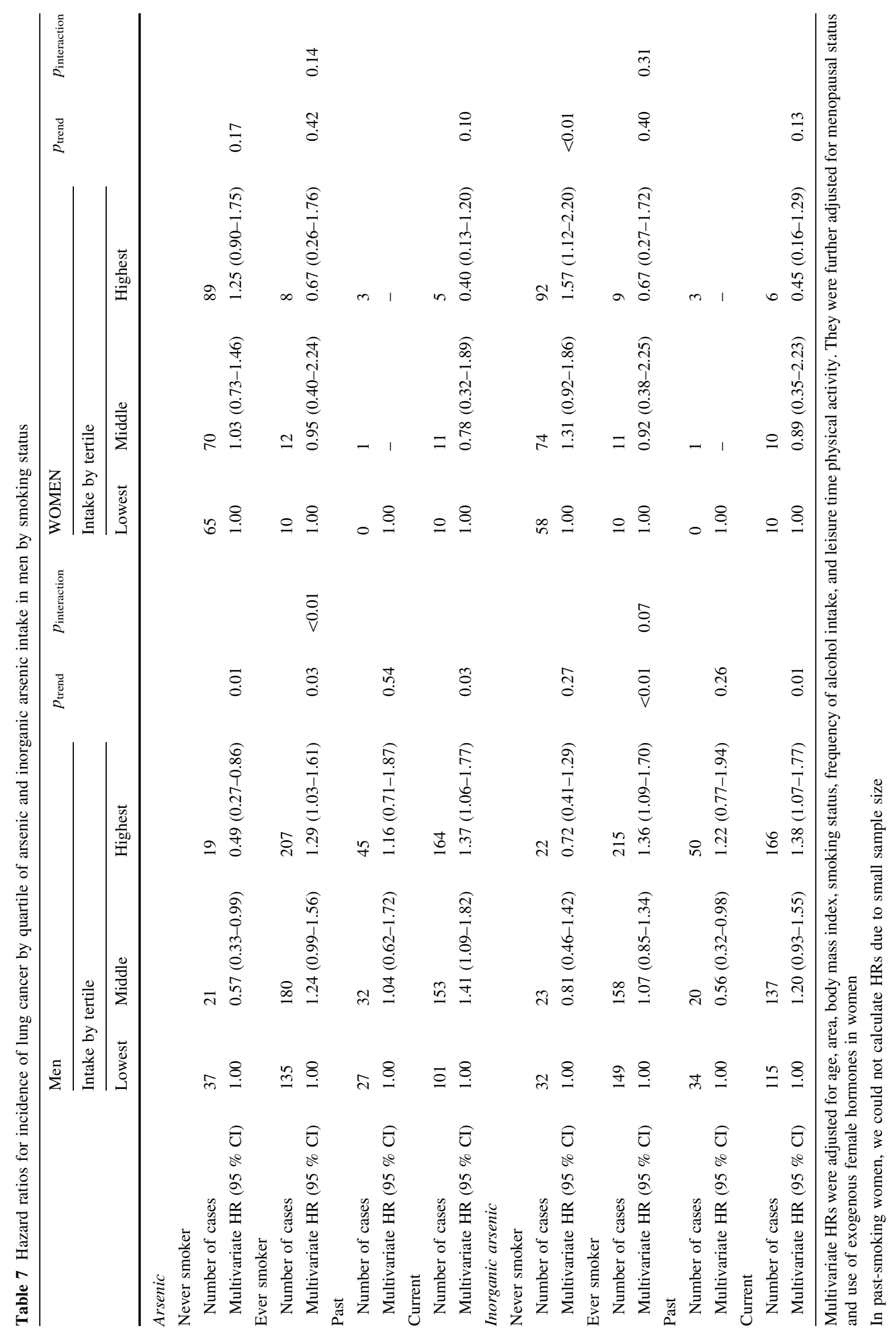


The results might be due to antioxidant effects of seaweeds without smoking.

In contrast, we observed a positive association between inorganic arsenic intake, hijiki intake, and lung cancer among never-smoking women. Lung adenocarcinoma in adult female mice exposed to arsenic showed higher ER $\alpha$ expression than lung tissue cells of unexposed animals [54]. Given that many studies have suggested an association between female hormonal factors and the risk of lung cancer in women, and the high proportion of lung adenocarcinoma in never-smoking women in our study (71\%), it is possible that arsenic increases the risk of lung cancer through a mechanism associated with female hormones. However, given the low validity between arsenic intake by FFQ and DR in women, we cannot rule out the possibility that this result occurred by chance.

Average dietary arsenic exposure was higher in our study $(170 \mu \mathrm{g} / \mathrm{day})$ than that reported in other countries, where mean daily adult intake of arsenic in food is estimated to range from 16.7 to $129 \mu \mathrm{g}$ [55]. Further, arsenic intake in our study was similar to that calculated by a duplicate-portion estimation (178 $\mu \mathrm{g} /$ day) [29], indicating the accuracy of our assessment of dietary arsenic exposure. Although duplicate-portion collection provides precise measurement, it is disadvantaged by its heavy burden on sample donors, which hampers sampling of large populations and accordingly limits case numbers and analysis of specific cancer sites. Arsenic intake as evaluated by FFQ is a reasonable way of estimating arsenic exposure in large cohort studies.

The major strengths of our study are its prospective design, high response rate $(80 \%)$, and negligible proportion of loss to follow-up $(0.3 \%)$. Other strengths were that information on arsenic intake was collected before the subsequent diagnosis of cancer, thereby diminishing the probability of the recall bias that is inherent to case-control studies. Further, the quality of our cancer registry system was satisfactory over the study period.

Several potential limitations of this analysis warrant mention. First, misclassification of exposure due to changes in arsenic intake during the study period might have occurred, because information on consumption was obtained at one point only. The main sources of inorganic arsenic in the Japanese diet are hijiki and rice, but few Japanese have any clear understanding of this. Thus, such misclassification would probably be nondifferential and may underestimate the true relative risk. On the other hand, misclassification due to low Spearman's rank correlation coefficient might also have occurred, particularly in women. It is possible that we did not precisely evaluate the association between arsenic intake and cancer among women and may be accordingly unable to conclude that there is no association between arsenic intake and cancer in women. Second, analyses by site of cancer are limited by the low number of cases and restricted statistical power, leading to somewhat imprecise estimates, albeit that the study cohort is large. A larger sample size might have detected the positive effects of arsenic on some cancers with greater precision, particularly in women. Moreover, we could not analyze the association between arsenic intake and rare cancers. Finally, the positive association between arsenic intake and lung cancer in current-smoking men might have occurred by chance, because of multiple testing. This is unlikely, however, because previous papers and mechanism support our results.

In conclusion, this study found a significant doseresponse trend for the association of arsenic intake with lung cancer risk in men, which was prominent among smokers. Appropriate public health interventions such as cigarette smoking cessation programs are warranted.

Acknowledgments This study was supported by Management Expenses Grants from the Government to the National Cancer Center and Grants-in-Aid for Cancer Research and for the 3rd Term Comprehensive 10-year Strategy for Cancer Control. We wish to thank all staff members in each study area and in the central offices for their cooperation and technical assistance. We also wish to thank the Iwate, Aomori, Ibaraki, Niigata, Osaka, Kochi, Nagasaki, and Okinawa cancer registries for their provision of incidence data. Members of the JPHC Study Group (principal investigator: S. Tsugane): S. Tsugane, M. Inoue, T. Sobue, and T. Hanaoka, Research Center for Cancer Prevention and Screening, National Cancer Center, Tokyo; J. Ogata, S. Baba, T. Mannami, A. Okayama, and Y. Kokubo, National Cardiovascular Center, Suita; K. Miyakawa, F. Saito, A. Koizumi, Y. Sano, I. Hashimoto, T. Ikuta, and Y. Tanaba, Iwate Prefectural Ninohe Public Health Center, Ninohe; Y. Miyajima, N. Suzuki, S. Nagasawa, Y. Furusugi, and N. Nagai, Akita Prefectural Yokote Public Health Center, Yokote; H. Sanada, Y. Hatayama, F. Kobayashi, H. Uchino, Y. Shirai, T. Kondo, R. Sasaki, Y. Watanabe, Y. Miyagawa, Y. Kobayashi, and M. Machida, Nagano Prefectural Saku Public Health Center, Saku; Y. Kishimoto, E. Takara, T. Fukuyama, M. Kinjo, M. Irei, and H. Sakiyama, Okinawa Prefectural Chubu Public Health Center, Okinawa; K. Imoto, H. Yazawa, T. Seo, A. Seiko, F. Ito, F. Shoji, and R. Saito, Katsushika Public Health Center, Tokyo; A. Murata, K. Minato, K. Motegi, and T. Fujieda, Ibaraki Prefectural Mito Public Health Center, Mito; T. Abe, M. Katagiri, M. Suzuki, and K. Matsui, Niigata Prefectural Kashiwazaki and Nagaoka Public Health Center, Kashiwazaki and Nagaoka; M. Doi, A. Terao, Y. Ishikawa, and T. Tagami, Kochi Prefectural Chuo-higashi Public Health Center, Tosayamada; H. Doi, M. Urata, N. Okamoto, F. Ide, and H. Sueta, Nagasaki Prefectural Kamigoto Public Health Center, Arikawa; H. Sakiyama, N. Onga, H. Takaesu, and M. Uehara, Okinawa Prefectural Miyako Public Health Center, Hirara; F. Horii, I. Asano, H. Yamaguchi, K. Aoki, S. Maruyama, M. Ichii, and M. Takano, Osaka Prefectural Suita Public Health Center, Suita; S. Matsushima and S. Natsukawa, Saku General Hospital, Usuda; M. Akabane, Tokyo University of Agriculture, Tokyo; M. Konishi, K. Okada, and I. Saito, Ehime University, Toon; H. Iso, Osaka University, Suita; Y. Honda, K. Yamagishi, S. Sakurai, and N. Tsuchiya, Tsukuba University, Tsukuba; H. Sugimura, Hamamatsu University, Hamamatsu; Y. Tsubono, Tohoku University, Sendai; M. Kabuto, National Institute for Environmental Studies, Tsukuba; S. Tominaga, Aichi Cancer Center Research Institute, Nagoya; M. Iida, W. Ajiki, and A. Ioka, Osaka Medical Center for Cancer and Cardiovascular 
Disease, Osaka; S. Sato, Osaka Medical Center for Health Science and Promotion, Osaka; N. Yasuda, Kochi University, Nankoku; K. Nakamura, Niigata University, Niigata; S. Kono, Kyushu University, Fukuoka; K. Suzuki, Research Institute for Brain and Blood Vessels Akita, Akita; Y. Takashima and M. Yoshida, Kyorin University, Mitaka; E. Maruyama, Kobe University, Kobe; M. Yamaguchi, Y. Matsumura, S. Sasaki, and S. Watanabe, National Institute of Health and Nutrition, Tokyo; T. Kadowaki, Tokyo University, Tokyo; M. Noda and T. Mizoue, International Medical Center of Japan, Tokyo; Y. Kawaguchi, Tokyo Medical and Dental University, Tokyo; and H. Shimizu, Sakihae Institute, Gifu.

Open Access This article is distributed under the terms of the Creative Commons Attribution License which permits any use, distribution, and reproduction in any medium, provided the original author(s) and the source are credited.

\section{References}

1. World Health Organization (1981) Arsenic. In: Environmental health criteria. Geneva SWHO. http://www.inchem.org/documents/ehc/ehc/ehc018.htm\#PartNumber:1

2. International Agency for Research on Cancer (1993) Some drinking-water disinfectants and contaminants, including arsenic, vol 84

3. Huang YK, Huang YL, Hsueh YM, Yang MH, Wu MM, Chen SY, Hsu LI, Chen CJ (2008) Arsenic exposure, urinary arsenic speciation, and the incidence of urothelial carcinoma: a twelveyear follow-up study. Cancer Causes Control 19(8):829-839. doi: 10.1007/s10552-008-9146-5

4. Chen CL, Chiou HY, Hsu LI, Hsueh YM, Wu MM, Wang YH, Chen CJ (2010) Arsenic in drinking water and risk of urinary tract cancer: a follow-up study from northeastern Taiwan. Cancer Epidemiol Biomarkers Prev 19(1):101-110. doi:10.1158/10559965.EPI-09-0333

5. Chen CJ, Chuang YC, You SL, Lin TM, Wu HY (1986) A retrospective study on malignant neoplasms of bladder, lung and liver in blackfoot disease endemic area in Taiwan. Br J Cancer 53(3):399-405

6. Chen CL, Hsu LI, Chiou HY, Hsueh YM, Chen SY, Wu MM, Chen CJ (2004) Ingested arsenic, cigarette smoking, and lung cancer risk: a follow-up study in arseniasis-endemic areas in Taiwan. JAMA 292(24):2984-2990. doi:10.1001/jama.292.24. 2984

7. Chiou HY, Hsueh YM, Liaw KF, Horng SF, Chiang MH, Pu YS, Lin JS, Huang CH, Chen CJ (1995) Incidence of internal cancers and ingested inorganic arsenic: a seven-year follow-up study in Taiwan. Cancer Res 55(6):1296-1300

8. Chiou HY, Chiou ST, Hsu YH, Chou YL, Tseng CH, Wei ML, Chen CJ (2001) Incidence of transitional cell carcinoma and arsenic in drinking water: a follow-up study of 8,102 residents in an arseniasis-endemic area in northeastern Taiwan. Am J Epidemiol 153(5):411-418

9. Morales KH, Ryan L, Kuo TL, Wu MM, Chen CJ (2000) Risk of internal cancers from arsenic in drinking water. Environ Health Perspect 108(7):655-661

10. Tsuda T, Nagira T, Yamamoto M, Kurumatani N, Hotta N, Harada M, Aoyama H (1989) Malignant neoplasms among residents who drank well water contaminated by arsenic from a king's yellow factory. J UOEH 11(Suppl):289-301

11. Tsuda T, Babazono A, Yamamoto E, Kurumatani N, Mino Y, Ogawa T, Kishi Y, Aoyama H (1995) Ingested arsenic and internal cancer: a historical cohort study followed for 33 years. Am J Epidemiol 141(3):198-209

12. Nakadaira H, Endoh K, Katagiri M, Yamamoto M (2002) Elevated mortality from lung cancer associated with arsenic exposure for a limited duration. J Occup Environ Med 44(3):291-299

13. Smith AH, Goycolea M, Haque R, Biggs ML (1998) Marked increase in bladder and lung cancer mortality in a region of Northern Chile due to arsenic in drinking water. Am J Epidemiol 147(7):660-669

14. Marshall G, Ferreccio C, Yuan Y, Bates MN, Steinmaus C, Selvin S, Liaw J, Smith AH (2007) Fifty-year study of lung and bladder cancer mortality in Chile related to arsenic in drinking water. J Natl Cancer Inst 99(12):920-928. doi:10.1093/jnci/djm004

15. Hopenhayn-Rich C, Biggs ML, Fuchs A, Bergoglio R, Tello EE, Nicolli H, Smith AH (1996) Bladder cancer mortality associated with arsenic in drinking water in Argentina. Epidemiology 7(2):117-124

16. Hopenhayn-Rich C, Biggs ML, Smith AH (1998) Lung and kidney cancer mortality associated with arsenic in drinking water in Cordoba. Argentina. Int J Epidemiol 27(4):561-569

17. Bates MN, Smith AH, Cantor KP (1995) Case-control study of bladder cancer and arsenic in drinking water. Am J Epidemiol 141(6):523-530

18. Mostafa MG, McDonald JC, Cherry NM (2008) Lung cancer and exposure to arsenic in rural Bangladesh. Occup Environ Med 65(11):765-768. doi:10.1136/oem.2007.037895

19. Schrauzer GN, White DA, Schneider CJ (1977) Cancer mortality correlation studies-IV: associations with dietary intakes and blood levels of certain trace elements, notably Se-antagonists. Bioinorg Chem 7(1):35-56

20. Kaise TOY, Ochi T, Okubo T, Hanaoka K, Irgolic KJ, Sakurai T, Matsubara C (1996) Toxicological study of organic arsenic compound in marine algae using mammalian cell culture technique. J Food Hyg Soc Jpn 37:135-141

21. Wei C, Li W, Zhang C, Van Hulle M, Cornelis R, Zhang X (2003) Safety evaluation of organoarsenical species in edible Porphyra from the China Sea. J Agric Food Chem 51(17): 5176-5182. doi:10.1021/jf026117j

22. Almela C, Algora S, Benito V, Clemente MJ, Devesa V, Suner MA, Velez D, Montoro R (2002) Heavy metal, total arsenic, and inorganic arsenic contents of algae food products. J Agric Food Chem 50(4):918-923

23. Almela C, Clemente MJ, Velez D, Montoro R (2006) Total arsenic, inorganic arsenic, lead and cadmium contents in edible seaweed sold in Spain. Food Chem Toxicol 44(11):1901-1908. doi:10.1016/j.fct.2006.06.011

24. Narukawa T, Hioki A, Chiba K (2012) Aqueous Extraction of Water-soluble Inorganic Arsenic in Marine Algae for Speciation Analysis. Anal Sci 28(8):773-779

25. Tsugane S, Sobue T (2001) Baseline survey of JPHC studydesign and participation rate. Japan Public Health Center-based Prospective Study on Cancer and Cardiovascular Diseases. J Epidemiol 11(6 Suppl):S24-S29

26. Reports from Ministry of Agriculture FaF (2006) http://www. maff.go.jp/j/press/cont2/pdf/20060310press_2b.pdf

27. Ishizaki M (1979) Arsenic content in foods on the market and its average daily intake (author's transl). Nihon Eiseigaku Zasshi 34(4):605-611

28. Reports from Nagaoka city (2008) http://www.city.nagaoka. niigata.jp/kurashi/suido/water-all.pdf

29. Reports from the Cabinets Office's Food Safety Commission (in Japanese) (2009) http://www.fsc.go.jp/fsciis/attachedFile/download? retrievalId $=$ cho20090120001\&fileId $=002$

30. The Council for Science and Technology MoE, Sports, Science and Technology J (2005) Standard tables of food composition in Japan, 5th revised and enlarged ed 
31. Willett WC (1998) Nutritional epidemiology, 2nd edn. Oxford University Press, New York

32. Heck JE, Andrew AS, Onega T, Rigas JR, Jackson BP, Karagas MR, Duell EJ (2009) Lung cancer in a U.S. population with low to moderate arsenic exposure. Environ Health Perspect 117(11):1718-1723. doi:10.1289/ehp.0900566

33. Chen CJ, Chen CW, Wu MM, Kuo TL (1992) Cancer potential in liver, lung, bladder and kidney due to ingested inorganic arsenic in drinking water. Br J Cancer 66(5):888-892

34. Kurttio P, Pukkala E, Kahelin H, Auvinen A, Pekkanen J (1999) Arsenic concentrations in well water and risk of bladder and kidney cancer in Finland. Environ Health Perspect 107(9): 705-710

35. Chen YC, Su HJ, Guo YL, Houseman EA, Christiani DC (2005) Interaction between environmental tobacco smoke and arsenic methylation ability on the risk of bladder cancer. Cancer Causes Control 16(2):75-81. doi:10.1007/s10552-004-2235-1

36. Hsueh YM, Huang YL, Huang CC, Wu WL, Chen HM, Yang MH, Lue LC, Chen CJ (1998) Urinary levels of inorganic and organic arsenic metabolites among residents in an arseniasishyperendemic area in Taiwan. J Toxicol Environ Health A 54(6): 431-444

37. Andrew AS, Burgess JL, Meza MM, Demidenko E, Waugh MG, Hamilton JW, Karagas MR (2006) Arsenic exposure is associated with decreased DNA repair in vitro and in individuals exposed to drinking water arsenic. Environ Health Perspect 114(8):11931198

38. Banerjee M, Sarma N, Biswas R, Roy J, Mukherjee A, Giri AK (2008) DNA repair deficiency leads to susceptibility to develop arsenic-induced premalignant skin lesions. Int $\mathrm{J}$ Cancer 123(2):283-287. doi:10.1002/ijc.23478

39. Food Standards Agency (2010) Consumers advised not to eat hijiki seaweed (5 August 2010) http://www.food.gov.uk/newsupdates/news/2010/aug/hijikiseaweed

40. World Health Organization (1988) Summary of evaluations performed by the joint FAO/WHO Expert Committee on Food Additives

41. World Health Organization (2010) Summary report of the seventy-second meeting of JECFA

42. Steinmaus C, Yuan Y, Bates MN, Smith AH (2003) Case-control study of bladder cancer and drinking water arsenic in the western United States. Am J Epidemiol 158(12):1193-1201

43. Bates MN, Rey OA, Biggs ML, Hopenhayn C, Moore LE, Kalman D, Steinmaus C, Smith AH (2004) Case-control study of bladder cancer and exposure to arsenic in Argentina. Am J Epidemiol 159(4):381-389

44. Karagas MR, Tosteson TD, Morris JS, Demidenko E, Mott LA, Heaney J, Schned A (2004) Incidence of transitional cell carcinoma of the bladder and arsenic exposure in New Hampshire. Cancer Causes Control 15(5):465-472. doi:10.1023/B: CACO.0000036452.55199.a3

45. Hertz-Picciotto I, Smith AH, Holtzman D, Lipsett M, Alexeeff G (1992) Synergism between occupational arsenic exposure and smoking in the induction of lung cancer. Epidemiology 3(1): 23-31

46. Chiou HY, Hsueh YM, Hsieh LL, Hsu LI, Hsu YH, Hsieh FI, Wei ML, Chen HC, Yang HT, Leu LC, Chu TH, Chen-Wu C, Yang MH, Chen CJ (1997) Arsenic methylation capacity, body retention, and null genotypes of glutathione S-transferase M1 and T1 among current arsenic-exposed residents in Taiwan. Mutat Res 386(3):197-207

47. Hays AM, Srinivasan D, Witten ML, Carter DE, Lantz RC (2006) Arsenic and cigarette smoke synergistically increase DNA oxidation in the lung. Toxicol Pathol 34(4):396-404. doi:10.1080/ 01926230600824926

48. Sasaki S, Matsumura Y, Ishihara J, Tsugane S (2003) Validity of a self-administered food frequency questionnaire used in the 5-year follow-up survey of the JPHC Study Cohort I to assess dietary fiber intake: comparison with dietary records. J Epidemiol 13(1 Suppl):S106-S114

49. MacArtain P, Gill CI, Brooks M, Campbell R, Rowland IR (2007) Nutritional value of edible seaweeds. Nutr Rev 65(12 Pt 1):535-543

50. Fukuda S, Saito H, Nakaji S, Yamada M, Ebine N, Tsushima E, Oka E, Kumeta K, Tsukamoto T, Tokunaga S (2007) Pattern of dietary fiber intake among the Japanese general population. Eur J Clin Nutr 61(1):99-103. doi:10.1038/sj.ejen.1602505

51. Yuan YV, Walsh NA (2006) Antioxidant and antiproliferative activities of extracts from a variety of edible seaweeds. Food Chem Toxicol 44(7):1144-1150. doi:10.1016/j.fct.2006.02.002

52. Yamamoto I, Maruyama H, Moriguchi M (1987) The effect of dietary seaweeds on 7,12-dimethyl-benz[a]anthracene-induced mammary tumorigenesis in rats. Cancer Lett 35(2):109-118

53. Yang YJ, Nam SJ, Kong G, Kim MK (2010) A case-control study on seaweed consumption and the risk of breast cancer. Br J Nutr 103(9):1345-1353. doi:10.1017/S0007114509993242

54. Watson WH, Yager JD (2007) Arsenic: extension of its endocrine disruption potential to interference with estrogen receptor-mediated signaling. Toxicol Sci 98(1):1-4

55. WHO Guidelines for Drinking-water Quality (2013) Arsenic in drinking-water. http://www.who.int/water_sanitation_health/dwq/ chemicals/arsenic.pdf\#search $=$ 'arsenic + in + drinkingwater $+\mathrm{WHO}+$ guidelines 